\title{
Genetic polymorphisms of the sortase A gene and social-behavioural factors associated with caries in children: a case-control study
}

\author{
Li Xia Yu ${ }^{1,2+}$, Ye Tao ${ }^{1,2+}$, Rong Min Qiu ${ }^{1,2}$, Yan Zhou ${ }^{1,2}$, Qing Hui Zhi ${ }^{1,2}$ and Huan Cai Lin ${ }^{1,2^{*}}$
}

\begin{abstract}
Background: Streptococcus mutans (S. mutans) is the primary etiological agent of dental caries. Sortase is a transpeptidase that anchors several surface proteins to the $S$. mutans cell wall and has been shown to play a major role in cariogenicity. The purpose of this study was to explore the genetic polymorphisms of the sortase gene (srtA) and the social-behavioural factors associated with dental caries in children with S. mutans.

Methods: In this case-control study, $121 \mathrm{~S}$. mutans strains were separately selected from caries-free children and high-severity caries children for sequencing of the srtA gene. Social and behavioural data were collected by self-administered questionnaires. Genomic DNA was extracted from S. mutans strains and amplified by PCR to obtain the srtA gene. The purified PCR products were sequenced and analysed for mutations with ABI Variant Reporter software. The distribution of missense mutations and the mean of social-behavioural factors were compared between the groups. A multiple logistic regression model was used to control for confounding factors.

Results: The mutation frequencies at loci $168(P=0.023)$ and $470(P=0.032)$ were significantly different between the groups. The best-fitting model showed that greater age, high frequencies of solid sugar consumption, prolonged breastfeeding, a high proportion of visible plaque, and S. mutans with a T at locus 168 of the srtA gene were associated with high-severity caries in children $(P<0.05)$. Children carrying a $\mathrm{G}$ at locus 168 of $S$. mutans had a decreased risk for high-severity caries ( $\mathrm{OR}=0.32,95 \% \mathrm{Cl}=0.12-0.86)$ compared with those carrying a $\mathrm{T}$.

Conclusions: The present study suggested that the locus 168 missense mutation of the srtA gene may correlate with caries susceptibility in children with S. mutans. In addition, age, duration of breastfeeding, solid sugar consumption, and poor oral hygiene contributed to this complex disease.
\end{abstract}

Keywords: Caries, Gene polymorphisms, srtA, Streptococcus mutans

\section{Background}

Dental caries is the localised destruction of dental hard tissues by acidic by-products from bacterial fermentation of dietary carbohydrates [1]. Oral microorganisms, dietary habits and host susceptibility interact in the initiation and development of dental caries [2]. In general, socio-demographic variables, development characteristics, general upbringing, oral health related behaviour, oral hygiene and bacteria are known risk factors for the

\footnotetext{
*Correspondence: lin_hc@163.net

${ }^{\dagger}$ Equal contributors

'Department of Preventive Dentistry, Guanghua School of Stomatology, Sun Yat-Sen University, 56 Ling Yuan Road West, Guangzhou, China ${ }^{2}$ Guangdong Provincial Key Laboratory of Stomatology, Sun Yat-Sen University, Guangzhou, China
}

development of dental caries in children [3]. It is a common worldwide disease affecting children's health and well-being $[2,4,5]$, especially in China. The Third National Oral Health Survey in China showed that the prevalence of childhood caries in the 5-year-old age group was as high as $66 \%$ and that the mean number of decayed, missing and filled teeth (dmft) was 3.5 [6].

Streptococcus mutans (S. mutans) is the primary etiological agent of dental caries [7]. Although the association between S. mutans and dental caries seems convincing, some children with $S$. mutans do not manifest the disease, suggesting that $S$. mutans may vary in its ability to initiate caries. One important characteristic of S. mutans in the development of dental caries is its ability to adhere to the 
tooth surface. Pac is one of the cell wall-anchored surface proteins identified in S. mutans, and it is responsible for mediating the adherence of $S$. mutans to tooth surfaces [8]. Sortase A (SrtA), coded by the gene $\operatorname{srtA}$, has been shown to be a membrane-localized transpeptidase that covalently links protein Pac with a sorting signal to the cell wall and possesses important adherent functions that have been associated with cariogenicity $[9,10]$. S. mutans with a mutated $s r t A$ gene was shown to result in a marked reduction in the adhesion potential of $S$. mutans and the frequency of dental caries [11]. Because an important function of srtA is the adherence of $S$. mutans to the tooth surface, we hypothesized that the srtA gene of $S$. mutans might possess genetic polymorphisms related to different caries conditions.

Considering the complex etiology of dental caries, the virulence and colonization of $S$. mutans can be modulated by behavioural, social and environmental factors [12,13]. In this study, we aimed to explore the genetic polymorphisms of the srtA gene and the social-behavioural factors associated with dental caries in children with S. mutans.

\section{Methods}

\section{Calculation of study sample size}

A case-control group design was applied in this study. According to the study design, the formulas used to calculate the sequencing sample capacities are shown below [14].

$$
\begin{aligned}
& \text { Formula 1: } N=\frac{N^{\prime}}{4}\left(1+\sqrt{1+\frac{4}{N^{\prime} \delta}}\right)^{2} \\
& \text { Formula 2: } N^{\prime}=\frac{\left[Z_{a} \sqrt{(1+1 / C) \pi_{c}\left(1-\pi_{c}\right)}+Z_{\beta} \sqrt{\pi_{2}\left(1-\pi_{2}\right)+\pi_{1}\left(1-\pi_{1}\right) / C}\right.}{\left(\pi_{2}-\pi_{1}\right)^{2}} \\
& \text { Formula 3: } \pi_{c}=\frac{\pi_{2}+\pi_{1}}{2} \\
& \text { Formula 4: } \delta=\left|\pi_{1}-\pi_{2}\right|
\end{aligned}
$$

The number of children was set to be equal in the case and control groups. Thus, the value of $C$ was 1.0. The value of $\alpha$ was set at 0.05 , and the value of $\beta$ was set at 0.15 . The values of $\pi_{1}$ and $\pi_{2}$ referred to the predicted missense mutation rates of $s r t A$ in the control and case groups in the present study, respectively. Based on the rates of each missense mutation locus in the caries-free and caries-active groups of our previous work [15], the largest sample size was required when $\pi_{1}=0.6$ and $\pi_{2}=0.4$, respectively. It was therefore calculated that the sample size should be 121 children for each group. All statistical tests were two-sided.

Because this study aimed primarily to explore connections between missense mutations of $s r t A$ and the severity of caries in the children with $S$. mutans, only the children who carried $S$. mutans were analysed. To satisfy the required sample size, we calculated the number of children that was required for the epidemiological survey. The prevalence rate of caries (68\%) and non-caries (32\%) in young children [16], along with the prevalence rate of $S$. mutans in the caries-free group (37.5\%) and the caries-active group (75\%), were considered [17]. The minimum number of children required to investigate was therefore calculated to be 1,009 .

\section{Field investigation}

An epidemiological survey was carried out in Huadu District of Guangzhou in South China from October 2012 to June 2013. The study protocol was approved by the Ethics Committee of Guanghua School of Stomatology, Sun Yat-sen University (ERC-[2012]-13). The Huadu District is a new urban district that consists of four streets and six towns. There were 114 nursery schools in this district. A random cluster sampling technique was employed to select 19 schools according to the number of children that we needed to recruit. Only those children who were aged 36-47 months old, had lived in the district for more than six months, reported no systematic illness, and reported no antibiotic intake for at least the preceding one month were included in the study. All of the participating schools were informed of and consented to the study. After written parental consent was obtained, all eligible 3-year-old children in the participating schools were included in the study.

Caries development, enamel hypoplasia and visible plaque accumulation were determined by a single dentist (L.X. Yu). CPI probes, disposable mouth mirrors, and intra-oral LED light sources were used for the examinations. The status of the dental caries was recorded according to the World Health Organization criteria using $\mathrm{dmft}$ indexes [18]. In short, the presence of dental caries was recorded when there was an obvious lesion in a pit or fissure or on smooth surface of a tooth. A detectable softened wall or undermined enamel was also recorded as dental caries. Enamel hypoplasia was recorded using the criteria recommended by the Fédération Dentaire Internationale (FDI) for general epidemiological surveys [19]. Enamel hypoplasia included three types of defects: pits, grooves or missing enamel. Oral hygiene was assessed using the Visible Plaque Index (VPI) [20]. Four sites of distal, midmost and mesial of buccal surfaces and the midmost of the lingual surface of each tooth were examined to record the VPI. The percentage of the examined sites with visible plaque was calculated. Approximately $10 \%$ of the subjects were re-examined to assess the intra-examiner reliability. Pooled samples of dental plaque from each child were collected with sterile cotton swabs from the buccal surfaces of maxillary teeth. The samples were dispersed in a sterile fluid thioglycolate (FT) medium and taken to the laboratory on ice within $4 \mathrm{~h}$ of collection.

Data were collected using a self-administered questionnaire that was administered to the caregivers. The questionnaire consisted of four parts: socio-demographic characteristics (e.g., age and sex of children, occupation 
and education level of parents), developmental characteristics (e.g., gestational age, mode of delivery, weight at birth and enamel hypoplasia), general upbringing history (e.g., bottle-feeding experience and duration of breastfeeding) and oral health behaviour (e.g., solid sugar consumption, frequency of tooth brushing and use of toothpaste).

\section{Isolation of S. mutans}

Plaque samples were mixed and sonicated for $30 \mathrm{~s}$ and were dispersed to obtain a dilution series to $10^{-3}$ dilutions. For each sample, $50 \mu \mathrm{l}$ of the diluent was plated onto Mitis-Salivarius-Bacitracin (MSB) agar, supplemented with $20 \%$ sucrose and 0.2 units $/ \mathrm{ml}$ bacitracin and incubated anaerobically $\left(85 \% \mathrm{~N}_{2}, 5 \% \mathrm{CO}_{2}\right.$, and $10 \%$ $\mathrm{H}_{2}$ ) at $37^{\circ} \mathrm{C}$ for $3 \mathrm{~d}$ [21]. We randomly selected two colonies from each child according to the colony morphology and tested the colonies for their ability to ferment mannitol, sorbitol, raffinose, melibiose, and aesculin and for their ability to hydrolyse arginine [22]. The identified bacterial strains were subsequently streaked onto MSB agar and preserved in $50 \%$ glycerol at $-80^{\circ} \mathrm{C}$ before use.

\section{Defining the case and control groups}

To explore and compare the genetic polymorphisms in the srtA gene of $S$. mutans, children with distinct caries experiences were taken into consideration. A total of 121 caries-free children with $S$. mutans were randomly selected as the caries-free group, and 121 children with $\mathrm{dmft} \geq 6$ who were $S$. mutans-positive were selected to form the high-severity caries group. The $\mathrm{dmft}$ score of the high-severity group was in accordance with the category used in a previous study [23].

\section{Extraction of chromosomal DNA}

S. mutans strains were grown in $2 \mathrm{ml}$ of brain-heart infusion broth and incubated at $37^{\circ} \mathrm{C}$ under anaerobic conditions for $18 \mathrm{~h}$. Cells centrifuged from the BHI cultures were suspended in $5 \%$ Chelex100, treated with $10 \mu \mathrm{l}$ of $20 \mathrm{mg} / \mathrm{ml}$ proteinase $\mathrm{K}$ at $37^{\circ} \mathrm{C}$ for $1 \mathrm{~min}$, and then digested at $56^{\circ} \mathrm{C}$ for $1 \mathrm{~h}$, followed by boiling for $10 \mathrm{~min}$. The tubes were frozen on ice for $3 \mathrm{~min}$, and the suspension was centrifuged at $12,000 \mathrm{rpm}$ for $10 \mathrm{~min}$. The supernatant was obtained for PCR. The quality and quantity of DNA samples were measured with a UV spectrophotometer at $260 \mathrm{~nm}$ and $280 \mathrm{~nm}$. All DNA was stored at $-20^{\circ} \mathrm{C}$ before further analysis.

\section{Amplification and sequencing of the srtA gene}

The PCR primers designed by ABI Primer Designer V3.0 that were used to amplify the UA159 srtA gene are listed in Table 1. A 1,035 bp DNA fragment carrying the srtA gene was amplified from $S$. mutans strains. Due to the limitation of the length of sequencing reads, we amplified
Table 1 PCR primers used for detection of the srtA gene in S. mutans

\begin{tabular}{lll}
\hline Primer & Sequence $\left(\mathbf{5}^{\prime} \mathbf{- 3}^{\prime}\right)$ & Product size $(\mathbf{b p})$ \\
\hline Pair1-F & GACGTTTGGCAACTGGTGTG & 557 \\
Pair1-R & CCAAGCAATTAGGGCATTTC & \\
Pair2-F & CAATGAAAAAAGAACGTCAATCTA & 448 \\
Pair2-R & TGTGAAGATCCGGTCATACCA & \\
Pair3-F & CGGAATTGCCATTCCAGACT & 721 \\
Pair3-R & TCCGAAACTATCAAAGCAACAT & \\
\hline
\end{tabular}

and sequenced the gene in three fragments that contained overlapping sections.

The PCR reaction was carried out in a $25 \mu \mathrm{l}$ reaction volume. The components in the PCR reaction (final conc.) were $2.5 \mu \mathrm{l}$ of $10 \times$ PCR buffer, $0.2 \mathrm{mM}$ of dNTP mix, $1.5 \mathrm{mM} \mathrm{MgCl}_{2}, 0.2 \mu \mathrm{M}$ each primer, $100-400 \mathrm{ng}$ of genomic DNA as template, and $2 \mathrm{U}$ of Platinum $^{\circ}$ Taq DNA Polymerase (Invitrogen, CA, USA). The temperate was preheated at $95^{\circ} \mathrm{C} 5 \mathrm{~min}$. The PCR cycle was as follows: denaturation at $95^{\circ} \mathrm{C}$ for $30 \mathrm{~s}$, annealing at $60^{\circ} \mathrm{C}$ for $30 \mathrm{~s}$, and elongation at $72^{\circ} \mathrm{C}$ for $50 \mathrm{~s}$. A total of 50 cycles were performed, followed by a final elongation step at $72^{\circ} \mathrm{C}$ for $5 \mathrm{~min}$. Five microliters of each amplified products was analysed by electrophoresis on a 1.5\% agarose gel. The PCR products were purified using a QIAquick Gel Extraction Kit (QIAgen, Hilden, Germany). Ultimately, the products were sequenced by the Shanghai Life Technologies Biotechnology Company (Life Technologies, Shanghai, China). Variant Reporter software was used to analyse the sequencing results, and the $s r t A$ sequence of $S$. mutans UA159 was selected as a reference sequence.

\section{Statistical analysis}

Data analysis was carried out using the SPSS 16.0 software. Categorical and continuous variables were compared using a Chi-square test and an independent samples $t$ test, respectively. Bivariate and multivariate logistic analyses were used to calculate odds ratios (ORs) with their corresponding 95\% confidence intervals (CIs) and identify the factors associated with high-severity caries. Caries status was treated as the dependent variable $(0=$ caries free group, 1 = high-severity caries group). Independent variables were those factors that may have influenced caries status. Those independent variables with $P<0.2$, based on a bivariate logistic analysis, were tested further in a multiple logistic regression model. A $P$ value $<0.05$ for all two-sided statistical tests was considered significant.

\section{Results}

The statistical analysis of the socioeconomic demographic characteristics and developmental factors are shown in Table 2. In social indicators, we found significantly different distributions in the ages (in months) between the groups 
Table 2 Bivariate analysis of demographic, socio-economic and development characteristics in relation to caries status

\begin{tabular}{|c|c|c|c|c|c|c|c|c|}
\hline Variables & \multicolumn{2}{|c|}{$\begin{array}{l}\text { Controls }(n=121) \\
n(\%)\end{array}$} & \multicolumn{2}{|c|}{$\begin{array}{l}\text { Cases }(n=121) \\
n(\%)\end{array}$} & $x^{2}$ & P-value* & COR $(95 \% \mathrm{Cl})$ & P-value \\
\hline \multicolumn{9}{|c|}{ Part1 Demographic and socio-economic characteristics } \\
\hline Sex & & & & & 1.345 & 0.246 & & \\
\hline Males $^{\dagger}$ & 59 & $(48.8)$ & 69 & $(57.0)$ & & & & \\
\hline Females & 62 & $(51.2)$ & 52 & $(43.0)$ & & & $0.72(0.43-1.19)$ & 0.198 \\
\hline Mother's schooling & & & & & 1.369 & 0.242 & & \\
\hline$\geq 12$ years $^{\dagger}$ & 74 & $(61.2)$ & 65 & (53.7) & & & & \\
\hline$<12$ years & 47 & $(38.8)$ & 56 & $(46.3)$ & & & $0.74(0.44-1.23)$ & 0.242 \\
\hline Father's schooling & & & & & 3.615 & 0.057 & & \\
\hline$\geq 12$ years $^{\dagger}$ & 87 & $(71.9)$ & 73 & $(60.3)$ & & & & \\
\hline$<12$ years & 34 & $(28.1)$ & 48 & (39.7) & & & $0.59(0.35-1.02)$ & 0.058 \\
\hline Mother's occupation & & & & & 1.813 & 0.404 & & 0.413 \\
\hline Employer/Professional ${ }^{\dagger}$ & 8 & (6.6) & 14 & (11.6) & & & & \\
\hline Employee/Non-professional & 88 & $(72.7)$ & 84 & $(69.4)$ & & & $0.55(0.22-1.37)$ & 0.196 \\
\hline Unemployed & 25 & $(20.7)$ & 23 & $(19.0)$ & & & $0.53(0.19-1.48)$ & 0.224 \\
\hline Father's occupation & & & & & 3.503 & 0.173 & & 0.181 \\
\hline Employer/Professional ${ }^{\dagger}$ & 22 & $(18.2)$ & 29 & $(24.0)$ & & & & \\
\hline Employee/Non-professional & 92 & $(76.0)$ & 90 & $(74.4)$ & & & $0.74(0.40-1.39)$ & 0.350 \\
\hline \multirow[t]{2}{*}{ Unemployed } & 7 & $(5.8)$ & 2 & $(1.7)$ & & & $0.22(0.04-1.15)$ & 0.072 \\
\hline & \multicolumn{2}{|c|}{ Mean(SD) } & \multicolumn{2}{|c|}{ Mean(SD) } & $t$ test & & & \\
\hline Age (months) & 41.6 & $(2.9)$ & 43.4 & (3.6) & -4.285 & $<0.001^{* *}$ & 1.18(1.09-1.28) & $<0.001$ \\
\hline Mother's age at child's birth & 27.1 & (3.8) & 26.4 & (3.8) & 1.517 & $0.131^{* *}$ & $0.95(0.89-1.02)$ & 0.132 \\
\hline \multicolumn{9}{|c|}{ Part 2 Development characteristics } \\
\hline Gestational age & & & & & 0.066 & 0.797 & & \\
\hline$\geq 37$ weeks $^{\dagger}$ & 58 & $(47.9)$ & 60 & $(49.6)$ & & & & \\
\hline$<37$ weeks & 63 & $(52.1)$ & 61 & $(50.4)$ & & & $0.94(0.57-1.55)$ & 0.797 \\
\hline Mode of delivery & & & & & 0.281 & 0.596 & & \\
\hline Vaginal birth ${ }^{\dagger}$ & 73 & $(60.3)$ & 77 & (63.6) & & & & \\
\hline Caesarean birth & 48 & $(39.7)$ & 44 & $(36.4)$ & & & $0.87(0.52-1.46)$ & 0.596 \\
\hline Weight at birth & & & & & 2.381 & 0.123 & & \\
\hline$\geq 2500 \mathrm{~g}^{\dagger}$ & 118 & $(97.5)$ & 113 & (93.4) & & & & \\
\hline$<2500 \mathrm{~g}$ & 3 & $(2.5)$ & 8 & $(6.6)$ & & & $2.79(0.72-10.76)$ & 0.138 \\
\hline Enamel hypoplasia & & & & & - & - & & \\
\hline Not & 121 & $(100.0)$ & 120 & $(99.2)$ & & & & \\
\hline Yes & 0 & $(0.0)$ & 1 & $(0.8)$ & & & - & - \\
\hline
\end{tabular}

${ }^{*}$ Chi-square test, ${ }^{* *}$ Independent samples $t$ test.

COR (crude odds ratio), $\mathrm{Cl}$ (confidence interval), ${ }^{\dagger}$ Reference Category.

$(P<0.001)$. Among the variables representing children's oral health behaviour (Table 3 ), the duration of breastfeeding $(P=0.09)$, frequency of solid sugar consumption $(P<0.01)$ and the proportion of VPI $(P<0.01)$ were all significantly associated with caries risk.

In comparing the $s r t A$ sequences of the clinical strains with S. mutans UA159, a total of 38 single nucleotide substitutions were found, including 21 silent mutation sites and 17 missense mutation sites (Figure 1). The caries-free group was found to have 19 silent mutation sites and 11 missense mutation sites, whereas the high-severity caries group was found to have 20 silent mutation sites and 14 missense mutation sites. Only ten strains were identical to strain UA159; of these, five were from the caries-free group, and five were from the high-severity caries group. None of the 
Table 3 Bivariate analysis of general upbringing and oral health behaviour in relation to caries status

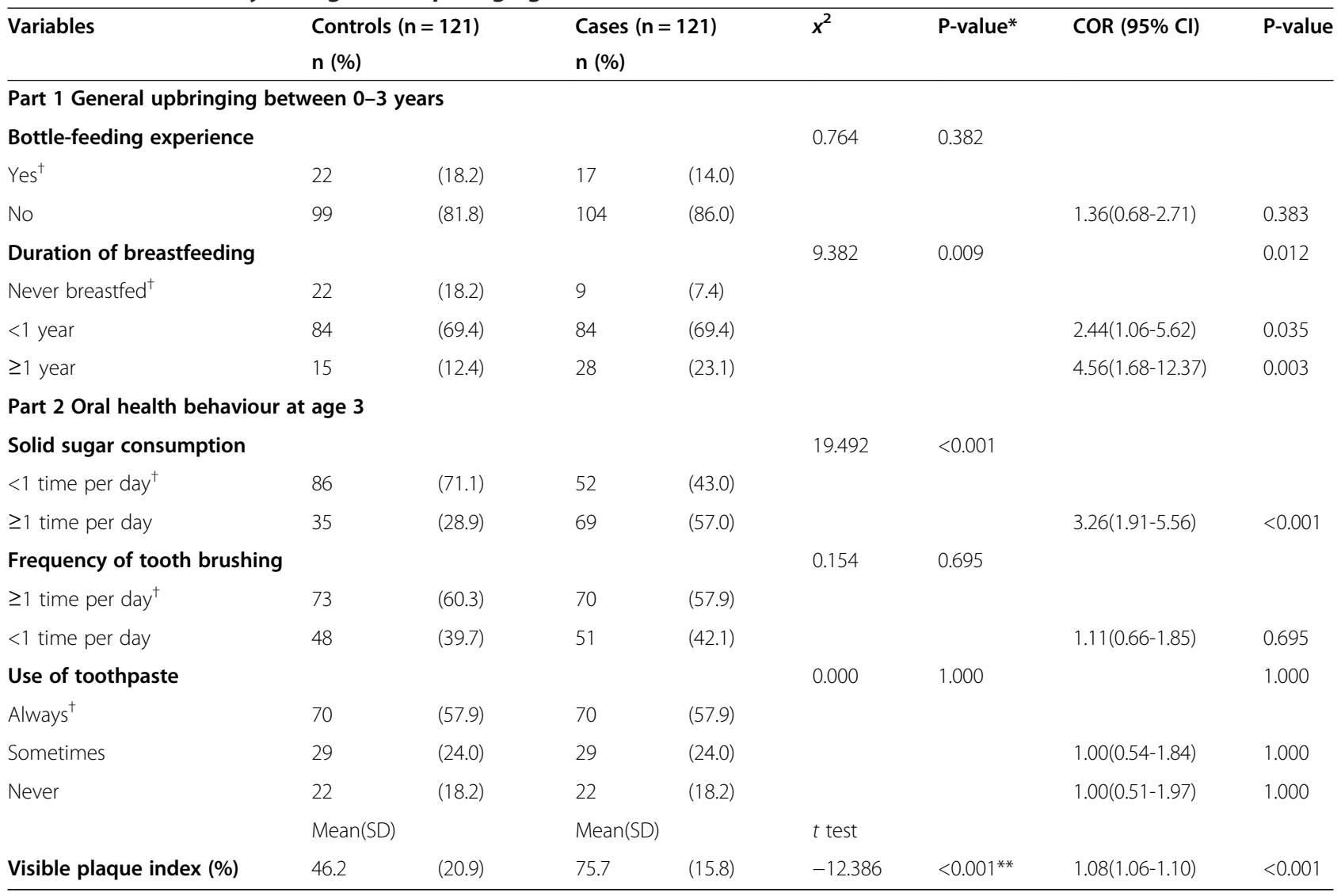

${ }^{*}$ Chi-square test, ${ }^{* *}$ Independent samples $t$ test.

$\mathrm{COR}$ (crude odds ratio), $\mathrm{Cl}$ (confidence interval), ${ }^{\dagger}$ Reference Category.

$\operatorname{srt} A$ genes in the sequences had a base insertion or deletion.

Silent mutation sites in the clinical strains were identified at positions $48,78,85,99,138,150,162,165,183,186,222$, $237,249,261,312,357,582,615,636,669$, and 717 .

Missense mutation sites in the clinical strains were identified at positions $23,34,36,47,100,112,114,168$, 176, 256, 298, 382, 470, 548, 584, 671, and 706. The amino acid transversions due to missense mutations are displayed in Table 4 . Here, we only show the alterations of amino acids due to missense mutations because these changes could affect the activity of sortase A.

The distribution frequencies of the missense mutation sites are listed in Table 5 . There was a significant difference in the mutation frequency at locus $168(P=0.023)$; the frequency of mutations at this site was significantly higher in the caries-free group than in the high-severity caries group. Moreover, strains with the locus 470 polymorphism exhibited a significantly higher rate in the high-severity caries group compared with the caries-free group $(P=0.032)$.

To control for confounding factors, multiple logistic regression analyses were performed, and the results (Table 6) showed that greater age $(P=0.027)$, high frequencies of solid sugar consumption $(P<0.001)$, prolonged breastfeeding $(P=0.028)$, a high proportion of visible plaque $(P<0.001)$, and $S$. mutans strains with a $\mathrm{T}$ at locus 168 of the $\operatorname{srt} A$ gene $(P=0.023)$ were significantly associated with high-severity caries in children. A lower risk of high-severity caries $(\mathrm{AOR}=0.32,95 \% \mathrm{CI}=$ 0.12-0.86) was found in children who carried S. mutans strains with a $\mathrm{G}$ at locus 168 of the $s r t A$ gene in comparison to a T. However, after controlling for confounding factors, the mutation at locus 470 was excluded from the model.

\section{Discussion}

The present study compared the genetic diversity in the $s r t A$ gene of $S$. mutans strains isolated from caries-free and high-severity caries children. Bivariate analysis of the present work showed that the mutation at locus 168 was overrepresented in the caries-free group and that the mutation at locus 470 was overrepresented in the high-severity caries group. Importantly, in our previous work [15], the mutation rate of locus 168 was higher in the caries-free group than in the caries-active group, and the mutation rate of locus 470 was higher in the caries-active group than in the caries-free group. The distributions in 


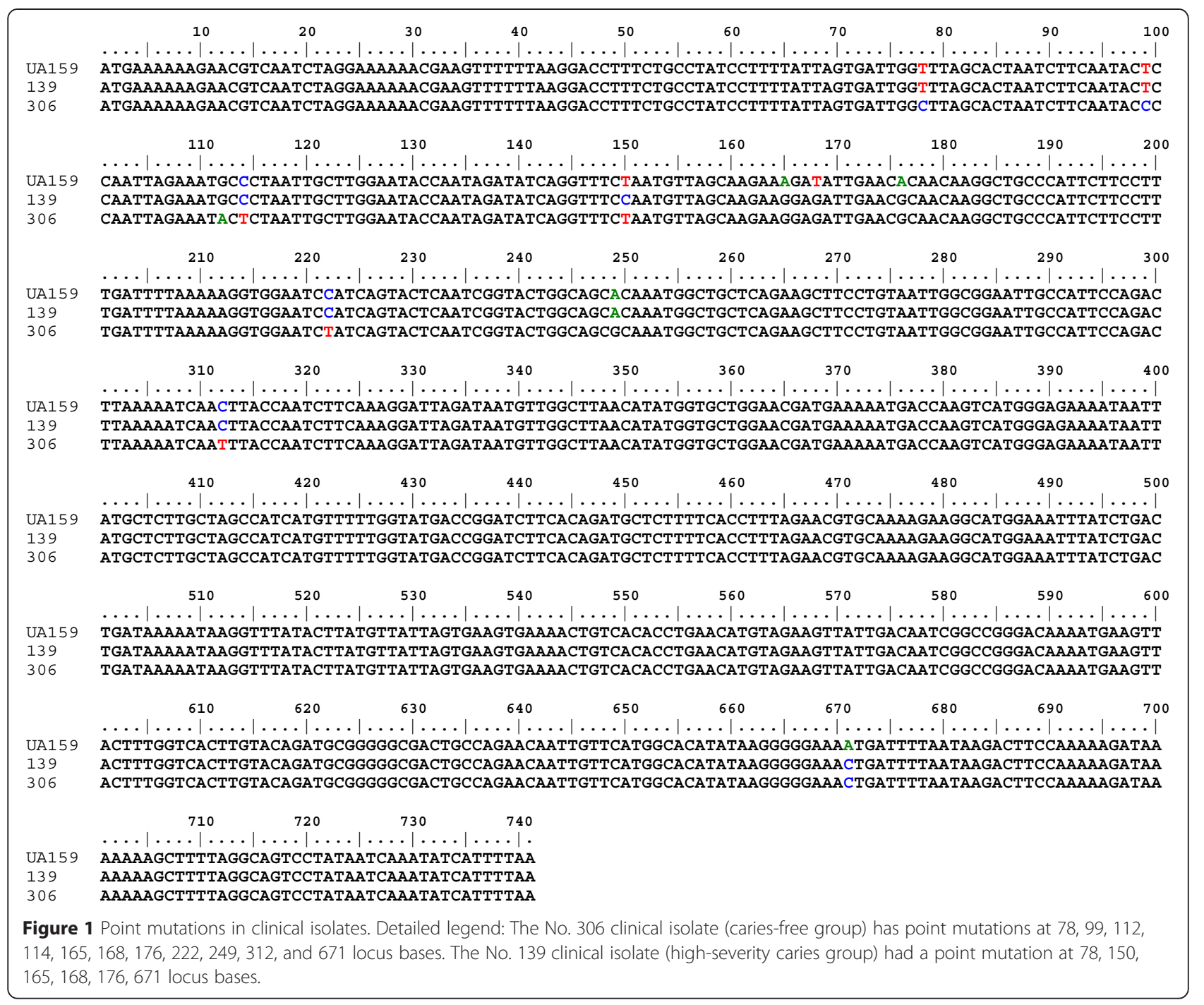

the mutation frequency of these two loci in the two groups were in accordance with the results of the present study.

Because bivariate analysis cannot exclude the confounding effect of other risk factors on caries in children, a multiple logistic regression was used. After adjusting for children's socio-demographics, developmental characteristics, general upbringing and oral health-related behavioural factors, the association between the $\operatorname{srt} A$ locus 470 polymorphisms and high-severity caries was abolished, but the association between the $\operatorname{srt} A$ locus 168 polymorphisms and high-severity caries remained. This result demonstrated that the $S$. mutans strains with a point mutation at locus 168 in $\operatorname{srt} A$ may have a lower risk for high-severity caries. It has been reported that $S$. mutans Ingbritt and NG5 preserved in the laboratory both have low cariogenicity due to the mutations in the $s r t A$ gene. Sequence analysis revealed that strain Ingbritt had an 11-nt deletion in the gene compared with strain GS5 [24] and strain NG5 had a single base substitution from $\mathrm{G}$ to $\mathrm{T}$ at the codon GAA, which codes for glutamic acid in NG8 [11]. Without a functional sortase, S. mutans strains were not able to perform several cell surfacerelated activities, including saliva-mediated adherence and aggregation $[11,24]$. Hence, we speculate that the point mutation at locus 168 may lead to a lower-activity sortase, which could affect the virulence of adherence and aggregation of $S$. mutans.

In this study, we aligned the nucleotide sequences of the $s r t A$ gene from clinical strains with those of strain UA159. The comparison showed that none of the clinical strains had base deletions, as observed for S. mutans Ingbritt. Although a single base substitution was a common occurrence in $S$. mutans, none of the clinical strains had nonsense mutations in the gene, as observed for S. mutans NG5. These results suggested that mutations in the $\operatorname{srt} A$ gene of laboratory strains Ingbritt and NG5 may be the consequences of long-term subculturing but are not a reflection of variation within the species in nature. 
Table 4 Transversion of amino acids due to missense mutations according to codons

\begin{tabular}{llllll}
\hline Base site & UA159 & & & \multicolumn{2}{l}{ Clinal strains } \\
\cline { 2 - 3 } \cline { 5 - 6 } & Codon & Amino acid & & Codon & Amino acid \\
\hline 23 & AGG & Arginine & & AAG & Lysine \\
34 & AGT & Serine & & GGC/GGT & Glycine \\
36 & AGT & Serine & & GGC/GGT & Glycine \\
47 & ACC & Threonine & & ATC & Isoleucine \\
100 & CCA & Proline & & TCA & Serine \\
112 & GCC & Alanine & & ACC/ACT & Threonine \\
114 & GCC & Alanine & & ACT & Threonine \\
168 & GAT & Asparaginic acid & GAG & Glutamic acid \\
176 & CAC & Histidine & & CGC & Arginine \\
256 & GCT & Alanine & & TCT & Serine \\
298 & GAC & Asparaginic acid & AAC & Asparagine \\
382 & GTC & Valine & & ATC & Isoleucine \\
470 & CGT & Arginine & CAT & Histidine \\
548 & GTC & Valine & GCC & Alanine \\
584 & CCG & Proline & CTG & Leucine \\
671 & AAT & Asparagine & ACT & Threonine \\
706 & GCT & Alanine & ACT & Threonine \\
\hline & & & &
\end{tabular}

Compared with our previous study that included a small sample [15], more mutation sites were found. All variant sites that had previously been discovered with the smaller sample sizes were identified again in this larger sample, which suggested that certain mutations in the $s r t A$ gene commonly occur in S. mutans strains. The greater number of mutation sites identified in the present study was likely due to the larger number of strains sequenced, which increased the probability of detecting different mutation sites.

In addition to bacterial genetic factors, the results of multiple logistic regression analyses revealed that other factors, including a greater age, prolonged breastfeeding, a high frequency of solid sugar consumption and visible plaque accumulation also contribute to caries in children with $S$. mutans. Older children have more caries because their teeth have been exposed to the environment and risks for a longer time. Although the relationship between prolonged breast-feeding and caries is controversial, prolonged breast-feeding may contribute to dental caries because it allows for the colonization of $S$. mutans [25] and because breast milk is more cariogenic than other types of milk [26]. The consumption of sugars has long been considered a cause of caries because it can be metabolized by $S$. mutans to produce the plaque dextrans essential for acid production [27]. Moreover, children with a higher proportion of VPI were more likely

Table 5 Bivariate analysis of the missense mutation rates in relation to caries status

\begin{tabular}{|c|c|c|c|c|c|c|c|c|}
\hline \multirow[t]{2}{*}{ Missense mutation } & \multicolumn{2}{|c|}{ Controls $(n=121)$} & \multicolumn{2}{|c|}{ Cases $(n=121)$} & \multirow[t]{2}{*}{$x^{2}$} & \multirow[t]{2}{*}{ P-value* } & \multirow[t]{2}{*}{ COR $(95 \% \mathrm{Cl})$} & \multirow[t]{2}{*}{ P-value } \\
\hline & n (\%) & & n (\%) & & & & & \\
\hline $23 \mathrm{G} \rightarrow \mathrm{A}^{\dagger}$ & 5 & (4.1) & 12 & $(9.9)$ & 3.100 & 0.078 & $2.55(0.87-7.49)$ & 0.087 \\
\hline $34 \mathrm{~A} \rightarrow \mathrm{G}$ & 7 & (5.8) & 10 & (8.3) & 0.569 & 0.450 & $0.68(0.25-1.85)$ & 0.453 \\
\hline $36 \mathrm{~T} \rightarrow \mathrm{C}$ & 6 & $(5.0)$ & 11 & $(9.1)$ & 1.582 & 0.209 & $1.92(0.69-5.36)$ & 0.215 \\
\hline $47 \mathrm{C} \rightarrow \mathrm{T}$ & 8 & (6.6) & 11 & $(9.1)$ & 0.514 & 0.473 & $1.41(0.55-3.64)$ & 0.475 \\
\hline $100 \mathrm{C} \rightarrow \mathrm{T}$ & 0 & $(0.0)$ & 1 & $(0.8)$ & - & $1.000^{* *}$ & - & 1.000 \\
\hline $112 \mathrm{G} \rightarrow \mathrm{A}$ & 71 & $(58.7)$ & 71 & (58.7) & 0.000 & 1.000 & $1.00(0.60-1.67)$ & 1.000 \\
\hline $114 \mathrm{C} \rightarrow \mathrm{T}$ & 65 & $(53.7)$ & 56 & $(46.3)$ & 1.339 & 0.247 & $0.74(0.45-1.23)$ & 0.248 \\
\hline $168 \mathrm{~T} \rightarrow \mathrm{G}$ & 26 & $(21.5)$ & 13 & $(10.7)$ & 5.166 & 0.023 & $0.44(0.21-0.90)$ & 0.025 \\
\hline $176 \mathrm{~A} \rightarrow \mathrm{G}$ & 63 & $(52.1)$ & 68 & $(56.2)$ & 0.416 & 0.519 & 1.18(0.71-1.96) & 0.519 \\
\hline $256 \mathrm{G} \rightarrow \mathrm{T}$ & 1 & $(0.8)$ & 0 & $(0.0)$ & - & $1.000^{* *}$ & - & 1.000 \\
\hline $298 \mathrm{G} \rightarrow \mathrm{A}$ & 1 & $(0.8)$ & 0 & $(0.0)$ & - & $1.000^{* *}$ & - & 1.000 \\
\hline $382 \mathrm{G} \rightarrow \mathrm{A}$ & 1 & $(0.8)$ & 0 & $(0.0)$ & - & $1.000^{* *}$ & - & 1.000 \\
\hline $470 \mathrm{G} \rightarrow \mathrm{A}$ & 7 & (5.8) & 17 & $(14.0)$ & 4.625 & 0.032 & $2.66(1.06-6.68)$ & 0.037 \\
\hline $548 \mathrm{~T} \rightarrow \mathrm{C}$ & 0 & $(0.0)$ & 1 & $(0.8)$ & - & $1.000^{* *}$ & - & 1.000 \\
\hline $584 \mathrm{C} \rightarrow \mathrm{T}$ & 0 & $(0.0)$ & 1 & $(0.8)$ & - & $1.000^{* *}$ & - & 1.000 \\
\hline $671 A \rightarrow C$ & 115 & $(95.0)$ & 116 & (95.9) & 0.095 & 0.758 & $0.83(0.25-2.78)$ & 0.758 \\
\hline $706 \mathrm{G} \rightarrow \mathrm{A}$ & 0 & $(0.0)$ & 1 & $(0.8)$ & - & $1.000^{* *}$ & - & 1.000 \\
\hline
\end{tabular}

${ }^{*}$ Chi-square test. ${ }^{* *}$ Fisher's exact test.

${ }^{\dagger} \mathrm{G} \rightarrow \mathrm{A}, \mathrm{G}$ represents the 23 locus base in UA159, A represents the 23 locus base in the clinical strains.

COR (crude odds ratio), $\mathrm{Cl}$ (confidence interval). 
Table 6 Summary of the multiple logistic regression results

\begin{tabular}{|c|c|c|c|c|c|c|}
\hline \multirow[t]{2}{*}{ Variables } & \multirow[t]{2}{*}{$\mathrm{B}^{\neq}$} & \multirow[t]{2}{*}{ SE } & \multirow[t]{2}{*}{$P$} & \multirow[t]{2}{*}{ AOR } & \multicolumn{2}{|c|}{$95 \% \mathrm{Cl}$ for $\mathrm{AOR}$} \\
\hline & & & & & Lower & Upper \\
\hline \multicolumn{7}{|l|}{ Mutations at locus 168} \\
\hline \multicolumn{7}{|l|}{$\mathrm{No}^{+}$} \\
\hline Yes & -1.156 & 0.510 & 0.023 & 0.32 & 0.12 & 0.86 \\
\hline Duration of breastfeeding & & & 0.028 & & & \\
\hline \multicolumn{7}{|l|}{ Never breastfed ${ }^{\dagger}$} \\
\hline$<1$ year & 1.273 & 0.651 & 0.050 & 3.57 & 1.00 & 12.79 \\
\hline$\geq 1$ year & 2.058 & 0.772 & 0.008 & 7.83 & 1.73 & 35.54 \\
\hline \multicolumn{7}{|l|}{ Solid sugar consumption } \\
\hline \multicolumn{7}{|l|}{$<1$ time per day ${ }^{\dagger}$} \\
\hline$\geq 1$ time per day & 1.911 & 0.427 & $<0.001$ & 6.76 & 2.93 & 15.61 \\
\hline Age (months) & 0.131 & 0.059 & 0.027 & 1.14 & 1.02 & 1.28 \\
\hline Visible Plaque Index (\%) & 0.090 & 0.012 & $<0.001$ & 1.09 & 1.07 & 1.12 \\
\hline Constant & -16.110 & 3.263 & $<0.001$ & 0.00 & & \\
\hline
\end{tabular}

${ }^{\dagger}$ Reference Category, ${ }^{\ddagger} \mathrm{B}$ : regression coefficient.

$\mathrm{SE}$ (standard error), AOR (adjusted odds ratio), $\mathrm{Cl}$ (confidence interval).

to have high-severity caries. Dental plaque retention increases $S$. mutans colonization such that there is an increase in the risk of caries [13]. This result was in accordance with those of previous studies [2,3].

There are limitations to the present study. The $\mathrm{dmft} \geq 6$ set as a cut-off value likely narrowed the selection of candidates for the caries active group. Further study is needed to clarify the mechanism of $\operatorname{srt} A$ gene mutation and dental caries.

\section{Conclusions}

The present study provided knowledge about the genetic diversity of the sortase $A$ gene of $S$. mutans in children with no caries and those with high-severity caries. The results of the study suggested that the locus 168 missense mutation of the $s r t A$ gene may correlate with caries susceptibility of children with $S$. mutans. In addition, age, duration of breastfeeding, solid sugar consumption, and poor oral hygiene also contributed to this complex disease.

\section{Availability of supporting data}

The nucleotide sequences of the srtA gene of $S$. mutans isolates determined in this study have been deposited in the GenBank database under the accession numbers KP301259 - KP301500.

\section{Abbreviations}

S. mutans: Streptococcus mutans; DNA: Deoxyribonucleic acid;

PCR: Polymerase chain reaction; WHO: World Health Organization; VPI: Visible Plaque Index; MSB: Mitis-Salivarius-Bacitracin agar; BHI: brain heart infusion broth; FDI: Federation Dentaire Internationale.

\section{Competing interests}

The authors declare that they have no competing interests.

\section{Authors' contributions}

LXY and YT contributed to the design of the study, the experiment conduct, data collection, data analysis and preparation of the manuscript. RMQ, YZ and $\mathrm{QHZ}$ contributed to the data collection and data analysis. $\mathrm{HCL}$ contributed to the conception and design of the study, general supervision of the research group, and critically revised the manuscript for important intellectual content. All authors read and approved the manuscript.

\section{Acknowledgements}

This study was supported by the National Natural Science Foundation of China (Grant No. 81271123).

Received: 14 December 2014 Accepted: 23 April 2015

Published online: 02 May 2015

\section{References}

1. Selwitz RH, Ismail Al, Pitts NB. Dental caries. Lancet. 2007;369:51-9.

2. Mulu W, Demilie T, Yimer M, Meshesha K, Abera B. Dental caries and associated factors among primary school children in Bahir Dar city: a cross-sectional study. BMC Res Notes. 2014;7:949.

3. Zhou Y, Lin HC, Lo EC, Wong MC. Risk indicators for early childhood caries in 2-year-old children in southern China. Aust Dent J. 2011;56:33-9.

4. Folayan MO, Chukwumah NM, Onyejaka N, Adeniyi AA, Olatosi OO. Appraisal of the national response to the caries epidemic in children in Nigeria. BMC Oral Health. 2014;14:76.

5. Struzycka I, Wierzbicka M, Jodkowska E, Rusyan E, Ganowicz E, Fidecki M. Oral health and prophylactic-therapeutic needs of children aged 6 years in Poland in 2012. Przegl Epidemiol. 2014;68:53-7.

6. Qi XQ. Report of the Third National Oral Health Survey in China (In Chinese). Beijing: People's Medical Publishing House; 2008. p. 60-1.

7. Krzysciak W, Jurczak A, Koscielniak D, Bystrowska B, Skalniak A. The virulence of Streptococcus mutans and the ability to form biofilms. Eur I Clin Microbiol Infect Dis. 2014;33:499-515.

8. Jenkinson HF, Demuth DR. Structure, function and immunogenicity of streptococcal antigen I/II polypeptides. Mol Microbiol. 1997;23:183-90.

9. Lee SF, Boran TL. Roles of sortase in surface expression of the major protein adhesin P1, saliva-induced aggregation and adherence, and cariogenicity of Streptococcus mutans. Infect Immun. 2003;71:676-81.

10. Igarashi T, Asaga E, Goto N. The sortase of Streptococcus mutans mediates cell wall anchoring of a surface protein antigen. Oral Microbiol Immunol. 2003;18:266-9. 
11. Lee SF, McGavin MK. Identification of a point mutation resulting in loss of cell wall anchoring activity of SrtA of Streptococcus mutans NG5. Infect Immun. 2004;72:4314-7.

12. Napimoga MH, Hofling JF, Klein Ml, Kamiya RU, Goncalves RB. Tansmission, diversity and virulence factors of Sreptococcus mutans genotypes. J Oral Sci. 2005:47:59-64.

13. Zhou Y, Yang JY, Zhi QH, Tao Y, Qiu RM, Lin HC. Factors associated with colonization of Streptococcus mutans in 8 to 32-month-old children: a cohort study. Aust Dent J. 2013;58:507-13.

14. Su Z. The sample size calculation and statistical analysis of case control study. In: Fang JQ, Sun ZQ, editors. Health Statistics (In Chinese). Beijing: People's Medical Publishing House; 2008. p. 347.

15. Zhang XH, Zhou Y, Zhi QH, Tao Y, Lin HC. Genetic polymorphisms of the sortase A gene and early childhood caries in two-year-old children. Arch Oral Biol. 2012;57:948-53.

16. Zhang R, Lin HC, Zhi QH. Caries prevalence of primary teeth and related factors in urban and rural young children of Guangzhou (In Chinese). Chin J Pract Stomatol. 2008;1:470-2.

17. Zhang $X H$, Zhou Y, Lin HC. Acquisition of Streptococcus mutans and cell adherence among 2-year old children with different caries experience (in Chinese). Chin J Pract Stomatol. 2009;2:727-9.

18. World Health Organization. Oral health survey, Basic Methods. 4th ed. Geneva: World Health Organization; 1997.

19. FDI Commission on Oral Health, Research and Epidemiology. A review of the developmental defects of enamel index (DDE index). Int Dent J. 1992:42:411-26.

20. Ainamo J, Bay I. Problems and proposals for recording gingivitis and plaque. Int Dent J. 1975;25:229-35.

21. Gold OG, Jordan HV, Van Houte J. A selective medium for Streptococcus mutans. Arch Oral Biol. 1973;18:1357-64.

22. Shklair IL, Keene HJ. A biochemical scheme for the separation of the five varieties of Streptococcus mutans. Arch Oral Biol. 1974;19:1079-81.

23. Martins-Junior PA, Vieira-Andrade RG, Correa-Faria P, Oliveira-Ferreira F, Marques LS, Ramos-Jorge ML. Impact of early childhood caries on the oral health-related quality of life of preschool children and their parents. Caries Res. 2013;47:211-8.

24. Igarashi T. Deletion in sortase gene of Streptococcous mutans Ingbritt. Oral Microbiol Immunol. 2004;19:210-3.

25. Vachirarojpisan T, Shinada K, Kawaguchi Y, Laungwechakan P, Somkote T, Detsomboonrat P. Early childhood caries in children aged 6-19 months. Community Dent Oral Epidemiol. 2004;32:133-42.

26. Bowen WH, Lawrence RA. Comparison of the cariogenicity of cola, honey, cow milk, human milk, and sucrose. Pediatrics. 2005;116:921-6.

27. Moye ZD, Zeng L, Burne RA. Fueling the caries process: carbohydrate metabolism and gene regulation by Streptococcus mutans. J Oral Microbiol. 2014;6:24878.

\section{Submit your next manuscript to BioMed Central and take full advantage of:}

- Convenient online submission

- Thorough peer review

- No space constraints or color figure charges

- Immediate publication on acceptance

- Inclusion in PubMed, CAS, Scopus and Google Scholar

- Research which is freely available for redistribution 